Cochrane Database of Systematic Reviews

\title{
Presurgery conditioning interventions (prehabilitation) in adults undergoing lower limb surgery for peripheral arterial disease (Protocol)
}

Palmer J, Pymer S, Smith GE, Harwood AE, Ingle L, Huang C, Chetter IC

Palmer J, Pymer S, Smith GE, Harwood AE, Ingle L, Huang C, Chetter IC.

Presurgery conditioning interventions (prehabilitation) in adults undergoing lower limb surgery for peripheral arterial disease.

Cochrane Database of Systematic Reviews 2019, Issue 9. Art. No.: CD013407.

DOI: 10.1002/14651858.CD013407.

www.cochranelibrary.com

Presurgery conditioning interventions (prehabilitation) in adults undergoing lower limb surgery for peripheral arterial disease (Protocol) Copyright @ 2019 The Cochrane Collaboration. Published by John Wiley \& Sons, Ltd. 


\title{
Presurgery conditioning interventions (prehabilitation) in adults undergoing lower limb surgery for peripheral arterial disease
}

\author{
Joanne Palmer ${ }^{1}$, Sean Pymer $^{1}$, George E Smith ${ }^{1}$, Amy Elizabeth Harwood ${ }^{1,2}$, Lee Ingle ${ }^{3}$, Chao Huang ${ }^{4}$, Ian C Chetter ${ }^{1}$ \\ ${ }^{1}$ Academic Vascular Surgical Unit, Hull York Medical School, Hull University Teaching Hospitals NHS Trust, Hull, UK. ${ }^{2}$ Thermal \\ Ergonomics Laboratory, Exercise and Sport Science, University of Sydney, Sydney, Australia. ${ }^{3}$ School of Life Sciences, University of \\ Hull, Hull, UK. ${ }^{4}$ Hull York Medical School, University of Hull, Hull, UK
}

Contact address: Joanne Palmer, Academic Vascular Surgical Unit, Hull York Medical School, Hull University Teaching Hospitals NHS Trust, Hull, HU3 2JZ, UK. joanne.palmer@hey.nhs.uk, hyjp17@hyms.ac.uk.

Editorial group: Cochrane Vascular Group.

Publication status and date: New, published in Issue 9, 2019.

Citation: Palmer J, Pymer S, Smith GE, Harwood AE, Ingle L, Huang C, Chetter IC. Presurgery conditioning interventions (prehabilitation) in adults undergoing lower limb surgery for peripheral arterial disease. Cochrane Database of Systematic Reviews 2019, Issue 9. Art. No.: CD013407. DOI: 10.1002/14651858.CD013407.

Copyright (C) 2019 The Cochrane Collaboration. Published by John Wiley \& Sons, Ltd.

\begin{abstract}
A B S T R A C T
This is a protocol for a Cochrane Review (Intervention). The objectives are as follows:

To assess the effectiveness of prehabilitation (preoperative exercise, either alone or in combination with nutritional or psychological interventions or both) on postoperative outcomes in adults with PAD undergoing open lower limb surgery.
\end{abstract}

\section{B A C K G R O U N D}

\section{Description of the condition}

Lower-limb peripheral arterial disease (PAD) is a type of cardiovascular disease in which the blood vessels (arteries) that carry blood to the legs are hardened and narrowed, or blocked by build-up of fatty plaques on the arterial wall (atherosclerosis) (Hiatt 2001). The most common symptom of PAD is intermittent claudication (IC). This is a muscle pain, fatigue, or discomfort in the calves, thigh, or buttocks that occurs during exercise and is relieved by rest. It occurs because there is an inability to match blood flow to demand and results in a lack of oxygen supply. Patients with IC often have a reduction in their physical activity, walking capacity, and quality of life. Risk factors for developing and contributing to a decline in health can be described as non-modifiable (including race, gender, age) or as modifiable (including smoking, diabetes mellitus, hypertension and high cholesterol). Current treatment for PAD is focused on preventing cardiovascular events, symptom relief, restoring mobility, improving functional ability, and improving overall quality of life. Early treatment options include risk factor management using pharmacotherapy, supervised exercise, smoking cessation, weight management, and surgical procedures (Norgren 2007).

However, PAD can be a progressive disease, approximately $10 \%$ to $20 \%$ of patients will have disease progression and $5 \%$ to $10 \%$ will lead on to critical limb ischaemia (CLI). CLI is characterised by intractable rest pain, non-healing wounds and ulceration, or gangrene, or both. The treatment options, when the limb is threat-

Presurgery conditioning interventions (prehabilitation) in adults undergoing lower limb surgery for peripheral arterial disease (Protocol) I

Copyright ( 2019 The Cochrane Collaboration. Published by John Wiley \& Sons, Ltd. 
ened or symptoms become unbearable are: angioplasty, bypass, and amputation surgical procedures (Norgren 2007). Whereas IC patients benefit from supervised exercise programmes (Lane 2017), patients with CLI, for whom surgical intervention is often the only option, most are often unable to exercise. This is as a result of being unable to maintain their physical fitness due to their disease progression and management of lifestyle factors, putting them at greater risk of poorer outcomes after surgery. Therefore this Cochrane Review will focus only on prehabilitation conducted to optimise the patient prior to undergoing an open surgical intervention for PAD.

\section{Prevalence and impact}

PAD affects more than 200 million people worldwide and is a common cause of vascular morbidity (Fowkes 2013). Total disease prevalence is approximately $3 \%$ to $5 \%$ of people aged above 40 , rising to $11 \%$ to $18 \%$ in people above 70 years of age (Selvin 2004). Of those with asymptomatic PAD, $5 \%$ to $10 \%$ will progress to CLI over a five-year period. The annual incidence of CLI is estimated at 220 to 3500 per 1,000,000 people, with a prevalence of approximately $1 \%$ of the population (Nehler 2014; Norgren 2007). PAD patients carry a high risk for surgical intervention, which may result in poor outcomes in mortality, morbidity, and length of hospital stay. Identified risk factors of poor surgical outcome in vascular patients include age, chronic obstructive pulmonary disease, coronary artery disease, inflammatory biomarker high sensitivity C-reactive protein, smoking, functional decline, and poor nutritional status (Ambler 2015; Hasanadka 2011; Luo 2016; Owens 2012). Surgical outcomes for vascular procedures have an in-hospital postoperative mortality rate of $2.8 \%$ to $5 \%$ (Waton 2017), but can be as high as $22 \%$ in bypass, below knee and above knee amputations respectively (Fortington 2013). Postoperative complications rates range from $14 \%$ in the UK, $19.9 \%$ in the USA, and as high as $30 \%$ in Europe; and re-admission rates vary between $7 \%$ to $18 \%$ (Fortington 2013; Kazaure 2016; Kehlet 2016; Waton 2017; Zhang 2014). A recent review that examined the surgical outcomes of bypass surgery for chronic lower limb ischaemia found that surgical outcomes did not reach statistical difference between type of procedure for mortality, patency, and amputation rates. However, the review did find a higher risk of complications (odds ratio (OR) 1.57) in the CLI group compared to the IC group (Antoniou 2017). Patients with CLI are also at greater risk of cardiac events due to the higher prevalence of atherosclerosis in other cardiovascular vessel beds (Farber 2016), indicating that the severity of the disease results in a poorer prognosis for patients with CLI. Therefore, if the number of studies are sufficient we will conduct a subgroup analysis for severity of PAD.

\section{Description of the intervention}

Prehabilitation is a multimodal conditioning intervention carried out prior to surgery. It consists of three components: exercise, nutritional care, and a psychological intervention (Minnella 2017). Prehabilitation is proposed as a means to enhance functional capacity with the intention to reduce postoperative morbidity and improve postsurgical recovery.

\section{Exercise}

Exercise includes regular physical activity that is incorporated into a structured programme with the specific goal of improving fitness. The exercise programme should include aerobic and strength training, whilst also including a flexibility component to encourage improvements in both functional reserve and the musculoskeletal system. Patients should engage in aerobic exercise three to five days per week, and strength training at least two days per week for between 30 and 60 minutes as recommended by the American College of Sports Medicine (Pescatello 2014). The exercise intervention should be overseen or delivered, or both, by either an exercise specialist or physiotherapist, and should commence up to 12 weeks prior to surgery, and be continued until the surgery date.

\section{Nutritional care}

Nutritional supplementation has three main functions; (i) to provide energy to enable the completion of aerobic exercise; (ii) for muscle repair; and (iii) adaptation and support the postoperative catabolic response to surgery. Patients who are malnourished have diminished protein and stored glycogen reserves that help to combat the metabolic stress of surgery (Gillis 2015). Carbohydrate supplementation may facilitate the completion of an exercise session via facilitation of supplementary protein. Protein supplementation will help to facilitate muscle repair and adaptation, with 1.2 $\mathrm{g}$ to $1.5 \mathrm{~g}$ protein $/ \mathrm{kg}$ demonstrated to support the postoperative catabolic response to surgery (Braga 2009). The nutritional status of the patient should be overseen by a dietician who can prescribe the required dose for each individual patient.

\section{Psychological interventions}

The primary aim of a psychological intervention is to reduce the anxiety and emotional burden of having surgery. A number of psychological characteristics such as mood, anxiety, health beliefs, and expectations have been suggested to influence postsurgery outcomes (Levett 2016). Psychological interventions, such as relaxation techniques, breathing exercises or meditation, as well as mindfulness, coping strategies, and cognitive behavioural therapy, may all play a role in anxiety reduction (Powell 2016). All psychological therapies should be delivered by an appropriately trained healthcare professional.

Presurgery conditioning interventions (prehabilitation) in adults undergoing lower limb surgery for peripheral arterial disease (Protocol)

Copyright ( 2019 The Cochrane Collaboration. Published by John Wiley \& Sons, Ltd. 


\section{How the intervention might work}

Patients undergoing major surgery, who have poor cardiorespiratory reserve levels due to low levels of fitness, may be at a higher risk of morbidity and mortality due to the elevated inflammatory response invoked by surgery. This response results in an increased demand in oxygen consumption in the postoperative period, which puts the body under additional stress (Le Roy 2016). Improving the fitness of a patient prior to surgery may aid the body to withstand this trauma, and providing nutritional supplementation may help patients to overcome the metabolic stress or facilitate any exercise training effects, or both. In addition, any surgical procedure is associated with an increased anxiety state in patients about their impending operation and ability to recover, therefore this period may provide an ideal window of opportunity to engage patients in activities to aid their recovery by reducing their emotional distress. This may be achieved through proactively engaging the patients in the preparation prior to their surgery (Carli 2010).

\section{Exercise}

Research shows that regular exercise increases aerobic capacity, antioxidant capacity, insulin sensitivity, and the ratio of lean body mass to body fat (Pierson 2001). Poor fitness scores preoperatively increase the chance of dying within 30 days postsurgery or at least result in a significantly longer stay in hospital with a greater chance of complications in cardiac and abdominal surgery (Cook 2001; Playforth 1987). A review of exercise interventions prior to abdominal and cardiac surgery found that prehabilitation resulted in fewer complications, shortened length of stay, improvements in health-related quality of life (QoL), and a mediation in the decline of functional disability (Carli 2005). Functional capacity reflects the underlying physiological reserve and provides an insight into the patient's ability to withstand the physiological stress of major surgery (Levett 2016). Engaging in physical activity prior to surgery has the potential to enhance physiologic reserve and facilitate postoperative recuperation (Carli 2015). Measures of exercise tolerance may indicate ability to withstand the increased oxygen demand after surgery. Peak oxygen consumption of less than 15 $\mathrm{mL} \cdot \mathrm{min}^{-1} \cdot \mathrm{kg}^{-1}$ and anaerobic threshold of less than $11 \mathrm{~mL} \cdot \mathrm{min}$ ${ }^{-1} \cdot \mathrm{kg}^{-1}$ have been associated with increased postoperative complications after major thoracic and abdominal surgery (Le Roy 2016). Similarly, values of $16.6 \mathrm{~mL} \cdot \mathrm{min}^{-1} \cdot \mathrm{kg}^{-1}$ and $11.8 \mathrm{~mL} \cdot \mathrm{min}^{-1} \cdot \mathrm{kg}$ ${ }^{-1}$ were found to be predictive of postoperative complications in abdominal aortic aneurysm repair patients (Barakat 2015).

\section{Nutritional care}

The primary goal of nutrition therapy is to optimise the nutrient stores preoperatively and to compensate for the catabolic response of surgery postoperatively. Current evidence highlights the role of whey protein in combating the inflammatory response (Yalçin 2006), and carbohydrate in avoiding insulin resistance and post- operative hyperglycaemia (Gupta 2016). The European Society for Clinical Nutrition and Metabolism recommends $1.2 \mathrm{~g}$ to 1.5 g protein/kg for surgical patients (Braga 2009). Whey protein is associated with an increase in protein synthesis, and plays a role in oxidative stress defence by increasing the content of intracellular stores of the antioxidant glutathione (GSH). GSH neutralizes reactive oxygen species (ROS), which aids the blunting of the inflammatory processes characteristic of the stress induced by surgery (Yalçin 2006). In a randomised controlled trial (RCT), colorectal cancer patients given a whey protein supplement of 10 $\mathrm{g}$ to $20 \mathrm{~g}$ a day, in combination with an exercise training programme for four weeks, demonstrated an improved functional performance postsurgery compared with controls (Gillis 2014). In addition, major surgical trauma results in a transient reduction of insulin sensitivity leading to an increase in glucose production, a decrease in tissue uptake of glucose, and glycogen synthesis due to hyperglycaemia, which significantly increases the risk of postoperative complications in patients undergoing cardiopulmonary bypass (Doenst 2005). As a result of the preoperative intake of carbohydrates, insulin resistance after cardiac surgery can be reduced due to stimulating insulin sensitivity before the operation (Sato 2010). Nutritional supplementation may therefore support a faster recovery from the metabolic stress of surgery, or improve the exercise training effect, or both.

\section{Psychological interventions}

Psychological stress induces a physiological response where the body's sympathetic nervous system is activated due to the release of hormones, adrenaline and noradrenaline. This causes an increase in heart rate, blood pressure, and respiratory rate and reduces the peripheral blood flow due to vasoconstriction. This process, if sustained for long periods, can have deleterious effects on patients with PAD (Aquarius 2006), where the peripheral blood flow is already compromised and patients are at a higher risk of cardiac complications (Barakat 2015). Several studies have identified that anxiety and depression can affect postoperative outcomes, such as wound healing in cancer and general surgical procedures (Cohen 2011; Munafo 2001; Walburn 2009). Potential mechanisms for these interventions vary dependent on the intervention used. Cognitive interventions aim to reduce negative emotions and thoughts related to the surgical process by either changing negative thoughts or refocusing attention elsewhere. Relaxation interventions aim to make an individual feel more relaxed, both psychologically and physiologically. Providing information about what is expected can have the potential to reduce anxiety by helping the patient to know what is normal when they undergo surgery (Powell 2016). All of these types of coping strategies can aid with the patients' ability to tolerate or eliminate psychological stress and its potential deleterious consequences. 


\section{Why it is important to do this review}

The prevalence of PAD has risen by $23 \%$ in the decade between 2000 and 2010 and is only set to increase in the future in light of an aging population and an increase in the prevalence of diabetes in the Western societies (Fowkes 2013). Despite advances in surgical technology, anaesthesia, and perioperative care, which has made surgery safer and more effective, there is still a proportion of patients who undergo surgery with a suboptimal recovery (Carli 2015). Since 2000, several studies have described the role of prehabilitation exercise therapy (Arthur 2000; Carli 2010; Dronkers 2010; Hulzebos 2006; Lemanu 2013; Santa Mina 2014; Valkenet 2011), exercise and nutrition (Carli 2005), exercise and psychological interventions (Bruns 2016), and all three components (Li 2013), with varying degrees of effectiveness in elderly patients having general and colorectal surgery. Whilst there has been much work in this area in recent years, the specific interventions (modality of exercise, exercise prescription, extent of supervision of exercise, choice of nutritional supplements, where used, and duration of intervention) vary widely between studies of prehabilitation in other patient groups, making it difficult to undertake any meaningful analyses (Bolshinsky 2018; Hijazi 2017). This specific patient group in this review are characterised by poor mobility and physical function, which will limit the diversity of exercise interventions possible. Thus we believe a systematic review of this population is timely and appropriate, and a meta-analysis may be possible. Additionally, this review will aim to synthesize evidence to identify relevant components of a prehabilitation programme that may be standardized to enable a meta-analysis to be undertaken in the future.

Currently there are no systematic reviews examining the evidence for the effectiveness of prehabilitation, including exercise with or without nutritional and psychological therapy in PAD patients undergoing lower limb surgery or its effectiveness on reducing mortality and morbidity. This Cochrane Review aims to assess the evidence for prehabilitation in lower limb vascular surgery and support future directions for research. In addition, as the PAD patient pathway is further complicated by the changing status of otherwise stable PAD with presentations of acute limb ischaemia (ALI), it is essential to know if and for whom prehabilitation will be of benefit. This will enable vascular surgeons to make informed decisions on the best management for their patients and provide a strategy to improve outcomes for the patients undergoing a surgical procedure.

\section{O B J E C T IVES}

To assess the effectiveness of prehabilitation (preoperative exercise, either alone or in combination with nutritional or psychological interventions or both) on postoperative outcomes in adults with PAD undergoing open lower limb surgery.

\section{METHODS}

\section{Criteria for considering studies for this review}

\section{Types of studies}

We will include all RCTs and quasi-RCTs on prehabilitation interventions with an exercise component or in combination with a nutritional or psychological component (together or separately) compared to control (standard treatment). Any methods of randomisation are eligible and we will take into account any differences in methodological quality in the analysis.

\section{Types of participants}

We will include all participants aged 18 years and older, diagnosed with PAD Fontaine Classifications II, IIA, IIB, III, and IV, or Rutherford Class 2 to 6, diagnosed by a clinician using a combination of general and systemic examination and diagnostic tools (ankle brachial pressure index, toe pressure index, doppler scan), who are undergoing lower limb surgery. We will include all open surgical bypass procedures including, but not limited to, supra and infrainguinal bypass and major amputations, including below, through, and above knee.

\section{Types of interventions}

We will include studies that compare any form of preoperative exercise alone, or in combination with, nutritional or psychological interventions (together or separately) with standard care. Standard care is a preoperative assessment and relevant preparation prior to surgery, which may include blood and urine tests and giving information on what will happen before, during, and after the operation.

Preoperative or prehabilitation exercise includes any intervention designed to improve fitness up to 12 weeks prior to the surgical procedure as an inpatient or outpatient. The exercise intervention may be individual or group, facility or home-based, or a combination thereof and only for the purpose of improving fitness for patients listed for surgery. Therefore exercise interventions for improving claudication symptoms only are excluded. We will exclude studies that compare the effectiveness of types of training, such as aerobic versus strength training, unless they also have a standard care arm.

Preoperative nutritional interventions include any intervention aimed at improving the nutritional status of individuals prior to surgery. These may include protein supplementation or carbohydrate loading, or both, prior to surgery; or whey protein supplementation to support exercise training.

Psychological interventions include any technique aimed at reducing the anxiety and stress of undergoing a surgical procedure.

Presurgery conditioning interventions (prehabilitation) in adults undergoing lower limb surgery for peripheral arterial disease (Protocol) 
Interventions may include inspiratory muscle training or breathing exercises, relaxation, meditation, visualisation or cognitive behavioural therapy, and smoking cessation. The smoking cessation intervention must be part of a psychological intervention, and will only be included if it is part of a prehabilitation programme in preparing the patient listed for surgery.

\section{Types of outcome measures}

\section{Primary outcomes}

- 30-day mortality: defined as all-cause death occurring within 30 days of the surgical procedure

- Postoperative complications

- Non-fatal cardiovascular events including myocardial infarction, heart failure, or stroke

- Pulmonary complications: postoperative pulmonary complications such as hypoxia, atelectasis, pneumonia, and respiratory failure

- Haemorrhage

- Surgical Site Infection (SSI)

- Any other complications not specified above

- Re-admission within 30 days

- Major adverse limb events (MALE), including

amputations or major re-intervention

$\circ$ Any other cause related to surgery

\section{Secondary outcomes}

- Survival at one year for all types of surgery

- Amputation-free survival in revascularisation procedures

- Changes in fitness or functional capacity, or both, preintervention and postintervention (measured by $\mathrm{VO}_{2 \text { peak }}$, ventilatory anaerobic threshold (VAT), grip strength, or submaximal exercise tests)

- Changes in psychological health presurgery and postsurgery (measured by validated questionnaires such as the hospital anxiety and depression scale, coping questionnaires, or psychological components in QoL scores)

- Changes in health-related QoL scores presurgery and postsurgery (measured by validated questionnaires such as the Short Form (SF) 36, SF12, or disease-specific tools such as the VascuQoL)

- Patient adherence and acceptability of exercise, nutritional, and psychological programmes (prehabilitation programmes) as reported by the study investigators

- Adverse events related to prehabilitation interventions

- Length of hospital stay

For all outcomes, we will include the time points reported by the individual studies. Clinically relevant time points will be baseline (presurgery), postintervention, and postsurgery at 30 days, and
3, 6, and 12 months. We will present outcomes that we do not include in any meta-analyses in narrative form.

\section{Search methods for identification of studies}

We will not apply any restrictions on language or publication status.

\section{Electronic searches}

The Cochrane Vascular Information Specialist will aim to identify all relevant RCTs and quasi-RCTs regardless of language or publication status (published, unpublished, in press, or in progress). The Information Specialist will search the following databases for relevant trials:

- Cochrane Vascular Specialised Register via the Cochrane Register of Studies (CRS-Web)

- Cochrane Central Register of Controlled Trials

(CENTRAL) in the Cochrane Register of Studies Online (CRSO)

- MEDLINE Ovid (from 1946 onwards)

- Embase Ovid (from 1974 onwards)

- CINAHL Ebsco (from 1982 onwards)

The Information Specialist has devised a draft search strategy for CENTRAL, which is displayed in Appendix 1. We will use this as the basis for search strategies for the other databases listed.

The Information Specialist will search the following trials registries:

- World Health Organization International Clinical Trials Registry Platform (who.int/trialsearch)

- ClinicalTrials.gov ( clinicaltrials.gov)

\section{Searching other resources}

We will review citations of included papers identified from the search strategy described above.

\section{Data collection and analysis}

\section{Selection of studies}

Two review authors (JP, SP) will independently assess the titles and abstracts of each study to identify those that meet the inclusion criteria. We will retrieve the full-text of the studies identified as potentially relevant by at least one review author. The same two review authors will independently screen the full-text articles retrieved for inclusion or exclusion. We will resolve any disagreements by discussion or, if necessary, we will consult a third review author $(\mathrm{AH})$. We will record the selection process and complete a

Presurgery conditioning interventions (prehabilitation) in adults undergoing lower limb surgery for peripheral arterial disease (Protocol) 5

Copyright (C) 2019 The Cochrane Collaboration. Published by John Wiley \& Sons, Ltd. 
PRISMA (Preferred Reporting Items for Systematic Reviews and Meta-Analyses) flow diagram.

\section{Data extraction and management}

Two review authors (JP, SP) will independently extract data from the eligible studies using an adapted data extraction form provided by Cochrane Vascular. We will resolve any disagreements by discussion or, if necessary, we will consult the third review author $(\mathrm{AH})$. One review author (JP) will enter the extracted data into Review Manager 5 (RevMan 2014). A second review author (SP), will check for accuracy and consistency against the data extraction sheets.

We will extract data from each included study on the following:

- Lead author, date

- Study participant inclusion/exclusion criteria

- Country where the research was conducted

- Participants gender and age

- Study design, randomisation processes, allocation concealment

- Recruitment rates

- Descriptions of interventions (type, length, adherence)

- Intervention settings (home, hospital, gym) and resources required (expertise and numbers of staff).

- Number of participants in each trial arm, withdrawals, dropouts, and loss to follow-up

- Length of follow-up

- Outcome measures and times outcomes were assessed

- Funding source

\section{Assessment of risk of bias in included studies}

Two review authors (JP, SP) will independently assess the risk of bias in each study using the following criteria, as recommended by the Cochrane Handbook for Systematic Reviews of Interventions (Higgins 2011).

- Random sequence generation (selection bias)

- Allocation concealment (selection bias)

- Blinding of participants and personnel (performance bias)

- Blinding of outcome assessment (detection bias)

- Incomplete outcome data (attrition bias)

- Selective outcome reporting (reporting bias)

- Other sources of bias

We will allocate each criterion a score of either low, high, or unclear risk of bias and will provide a statement to support each judgement. If there is disagreement between review authors, then a third review author $(\mathrm{AH})$ will resolve any issues. We will contact study authors should further information be required for the 'Risk of bias' assessment. We will assess the likely magnitude and direction of bias and whether it is likely to impact on findings using sensitivity analyses (see Sensitivity analysis). We will present
'Risk of bias' results using a 'Risk of bias' graph and a 'Risk of bias' summary.

\section{Measures of treatment effect}

\section{Dichotomous data}

We will analyse the data based on the number of the events and the number of people assessed in the intervention and comparison groups for dichotomous outcomes. We will use these to calculate the risk ratio (RR) or odds ratio (OR) and associated 95\% confidence intervals $(\mathrm{CIs})$ to reflect uncertainty of the estimate of effect.

\section{Continuous data}

We will analyse data based on the mean and standard deviation (SD) with corresponding $95 \%$ CIs to calculate the mean difference (MD) for continuous outcome measures. We will use standardised mean difference (SMD) with $95 \%$ CIs to combine data from trials that measure the same outcome using different scales (Higgins 2011).

\section{Time-to-event data}

We will use survival analysis to report time-to-event data and the intervention effect expressed as a hazard ratio (HR) and associated 95\% CIs. We will be guided by the methods used and described by Parmar 1998 and Tierney 2007.

\section{Unit of analysis issues}

We will consider the unit of analysis to be each individual participant.

\section{Dealing with missing data}

If possible, we will perform all analyses using an intention-to-treat approach, that is, we will analyse all participants and their outcomes within the groups to which they were allocated, regardless of whether they received the intervention. If required, we will contact study authors to request missing data. We will report levels of loss to follow-up and assess this as a source of potential bias.

\section{Assessment of heterogeneity}

We will assess the degree of heterogeneity by visual inspection of forest plots and by using the $\mathrm{Chi}^{2}$ test for heterogeneity. We will assess heterogeneity of the overall results for the main outcomes using the $\mathrm{Chi}^{2}, \mathrm{I}^{2}$ and $\mathrm{Tau}^{2}$ statistics, according to the Cochrane Handbook for Systematic Reviews of Interventions (Higgins 2011). We will regard statistical heterogeneity as substantial if the $\mathrm{I}^{2}$ statistic value is $>50 \%$, but we will interpret this value in light of the 
size and direction of effects and the strength of the evidence for heterogeneity based on the $\mathrm{P}$ value in the $\mathrm{Chi}^{2}$ test for heterogeneity also known as Q statistics. If we detect heterogeneity, we will explore possible reasons for it.

\section{Assessment of reporting biases}

We will investigate publication bias using funnel plots if 10 or more studies meet the inclusion criteria of the review, as recommended by the Cochrane Handbook for Systematic Reviews of Interventions (Higgins 2011).

\section{Data synthesis}

We will perform statistical analyses using Review Manager 5 (RevMan 2014). We will use fixed-effect meta-analyses for synthesising data where it is reasonable to assume that trials are estimating the same underlying treatment effect. If there is clinical heterogeneity sufficient to expect that the underlying treatment effects differ between trials, we will use random-effects meta-analyses to produce an overall summary where the mean treatment effect is clinically meaningful. If we identify clinical, methodological, or statistical heterogeneity across included trials sufficient to cause concerns, we will not report pooled results from the meta-analysis but will instead use a narrative approach to data synthesis.

\section{Subgroup analysis and investigation of heterogeneity}

We intend to perform the following subgroup analysis:

- Severity of ischaemia where participants have a Fontaine score of III or IV or a Rutherford score 4 to 6

- Type of surgical procedure

- Combinations of interventions used

- Location of where the intervention was delivered (home, gym, or hospital)

\section{Sensitivity analysis}

We will repeat the analyses including high-quality trials only. For this review, we will classify trials that we judge as being at low risk of bias for sequence generation and allocation concealment as highquality trials (Higgins 2011). We will also repeat the analyses with quasi-RCTs, which will allow us to further investigate any effects of including data from quasi-RCTs on the combined results.

\section{'Summary of findings' table}

Based on the methods described in Chapter 11 of the Cochrane Handbook for Systematic Reviews of Interventions (Higgins 2011), we will present the findings of this review in a 'Summary of findings' table. We will present results for the main comparisons of the review and for the following outcomes, which we consider to be of the greatest clinical relevance to both patients and health professionals.

- 30-day mortality

- Postoperative complications

- Re-admission within 30 days

- Survival at one year for all types of surgery

- Changes in fitness or functional capacity, or both, preintervention and postintervention

- Changes in psychological health presurgery and postsurgery

- Changes in health-related QoL scores presurgery and postsurgery

For each assumed risk cited in the table(s), we will provide a source and rationale. We will prepare the table using the GRADE profiler (GRADEpro GDT 2015). We will use the GRADE approach to assess the quality of the evidence as high, moderate, low, or very low based on the risk of bias, inconsistency, indirectness, imprecision, and publication bias (Atkins 2004; Higgins 2011). If meta-analysis is not possible, we will present the results in a narrative 'Summary of findings' table format. Please see Table 1 for an example 'Summary of findings' table.

\section{ACKNOWLEDGEMENTS}

The review authors and the Cochrane Vascular editorial base are grateful to the peer reviewers for their time and comments.

\section{RE F ER E N C E S}

\section{Additional references}

\section{Ambler 2015}

Ambler GK, Brooks DE, Al Zuhir N, Ali A, Gohel MS, Hayes PD, et al. Effect of frailty on short- and mid-term outcomes in vascular surgical patients. British Journal of Surgery 2015;102(6):638-45.

Antoniou 2017

Antoniou GA, Georgiadis GS, Antoniou SA, Makar RR,
Smout JD, Torella F. Bypass surgery for chronic lower limb ischaemia. Cochrane Database of Systematic Reviews 2017, Issue 4. DOI: 10.1002/14651858.CD002000.pub3

Aquarius 2006

Aquarius AE, De Vries J, Henegouwen DP, Hamming JF. Clinical indicators and psychosocial aspects in peripheral arterial disease. Archives of Surgery 2006;141(2):161-6.

Arthur 2000

Arthur HM, Daniels C, McKelvie R, Hirsh J, Rush B. 
Effect of a preoperative intervention on preoperative and postoperative outcomes in low-risk patients awaiting elective coronary artery bypass graft surgery. A randomized, controlled trial. Annals of Internal Medicine 2000;133(4): 253-62.

\section{Atkins 2004}

Atkins D, Best D, Briss PA, Eccles M, Falck-Ytter Y, Flottorp S, et al. Grading quality of evidence and strength of recommendations. BMJ 2004;328(7454):1490.

\section{Barakat 2015}

Barakat HM, Shahin Y, McCollum PT, Chetter IC. Prediction of organ-specific complications following abdominal aortic aneurysm repair using cardiopulmonary exercise testing. Anaesthesia 2015;70(6):679-85.

\section{Bolshinsky 2018}

Bolshinsky V, Li MH, Ismail H, Burbury K, Riedel B, Heriot A. Multimodal prehabilitation programs as a bundle of care in gastrointestinal cancer surgery: a systematic review. Diseases of the Colon and Rectum 2018;61(1): 124-38.

Braga 2009

Braga M, Ljungqvist $\mathrm{O}$, Soeters $\mathrm{P}$, Fearon K, Weimann A, Bozzetti F, et al. ESPEN Guidelines on Parenteral Nutrition: surgery. Clinical Nutrition (Edinburgh, Scotland) 2009;28(4):378-86.

\section{Bruns 2016}

Bruns ERJ, van den Heuvel B, Buskens CJ, van Duijvendijk P, Festen S, Wassenaar EB, et al. The effects of physical prehabilitation in elderly patients undergoing colorectal surgery: a systematic review. Colorectal Disease 2016;18(8): $267-77$.

\section{Carli 2005}

Carli F, Zavorsky GS. Optimizing functional exercise capacity in the elderly surgical population. Current Opinion in Clinical Nutrition and Metabolic Care 2005;8(1):23-32.

\section{Carli 2010}

Carli F, Charlebois P, Stein B, Feldman L, Zavorsky G, Kim DJ, et al. Randomized clinical trial of prehabilitation in colorectal surgery. British Journal of Surgery 2010;97(8): 1187-97.

\section{Carli 2015}

Carli F, Scheede-Bergdahl C. Prehabilitation to enhance perioperative care. Anesthesiology Clinics 2015;33(1):17-33.

\section{Cohen 2011}

Cohen L, Parker PA, Vence L, Savary C, Kentor D, Pettaway C, et al. Presurgical stress management improves postoperative immune function in men with prostate cancer undergoing radical prostatectomy. Psychosomatic Medicine 2011;73(3):218-25.

\section{Cook 2001}

Cook JW, Pierson LM, Herbert WG, Norton HJ, Fedor JM, Kiebzak GM, et al. The influence of patient strength, aerobic capacity and body composition upon outcomes after coronary artery bypass grafting. Thoracic and Cardiovascular Surgeon 2001;49(2):89-93.

\section{Doenst 2005}

Doenst T, Wijeysundera D, Karkouti K, Zechner C, Maganti M, Rao V, et al. Hyperglycemia during cardiopulmonary bypass is an independent risk factor for mortality in patients undergoing cardiac surgery. Journal of Thoracic and Cardiovascular Surgery 2005;130(4):1144.

\section{Dronkers 2010}

Dronkers JJ, Lamberts H, Reutelingsperger IMMD, Naber RH, Dronkers-Landman CM, Veldman A, et al. Preoperative therapeutic programme for elderly patients scheduled for elective abdominal oncological surgery: a randomized controlled pilot study. Clinical Rehabilitation 2010;24(7):614-22.

\section{Farber 2016}

Farber A, Eberhardt RT. The current state of critical limb ischemia: a systematic review. JAMA Surgery 2016;151(11): 1070-7.

\section{Fortington 2013}

Fortington LV, Geertzen JHB, van Netten JJ, Postema K, Rommers GM, Dijkstra PU. Short and long term mortality rates after a lower limb amputation. European Journal of Vascular and Endovascular Surgery 2013;46(1):124-31.

\section{Fowkes 2013}

Fowkes FGR, Rudan D, Rudan I, Aboyans V, Denenberg JO, McDermott MM, et al. Comparison of global estimates of prevalence and risk factors for peripheral artery disease in 2000 and 2010: a systematic review and analysis. Lancet 2013;382(9901):1329-40.

\section{Gillis 2014}

Gillis C, Li C, Lee L, Awasthi R, Augustin B, Gamsa A, et al. Prehabilitation versus rehabilitation: a randomized control trial in patients undergoing colorectal resection for cancer. Anesthesiology 2014;121(5):937-47.

\section{Gillis 2015}

Gillis C, Carli F. Promoting perioperative metabolic and nutritional care. Anesthesiology 2015;123(6):1455-72.

\section{GRADEpro GDT 2015 [Computer program]} McMaster University (developed by Evidence Prime). GRADEpro GDT. Version accessed 28 June 2018. Hamilton (ON): McMaster University (developed by Evidence Prime), 2015.

\section{Gupta 2016}

Gupta R, Gan TJ. Preoperative nutrition and prehabilitation. Anesthesiology Clinics 2016;34(1):143-53.

\section{Hasanadka 2011}

Hasanadka R, McLafferty RB, Moore CJ, Hood DB, Ramsey DE, Hodgson KJ. Predictors of wound complications following major amputation for critical limb ischemia. Journal of Vascular Surgery 2011;54(5):1374-82.

\section{Hiatt 2001}

Hiatt WR. Medical treatment of peripheral arterial disease and claudication. New England Journal of Medicine 2001; 344(21):1608-21. 


\section{Higgins 2011}

Higgins JP, Green S, editor(s). Cochrane Handbook for Systematic Reviews of Interventions Version 5.1.0 (updated March 2011). The Cochrane Collaboration, 2011. Available from handbook.cochrane.org.

\section{Hijazi 2017}

Hijazi Y, Gondal U, Aziz O. A systematic review of prehabilitation programs in abdominal cancer surgery. International Journal of Surgery 2017;39:156-62.

Hulzebos 2006

Hulzebos EHJ, Helders PJM, Favié NJ, De Bie RA, Brutel de la Riviere A, Van Meeteren NLU. Preoperative intensive inspiratory muscle training to prevent postoperative pulmonary complications in high-risk patients undergoing CABG surgery: a randomized clinical trial. JAMA 2006; 296(15):1851-7.

\section{Kazaure 2016}

Kazaure HS, Chandra V, Mell MW. Unplanned reoperations after vascular surgery. Journal of Vascular Surgery 2016;63 (3):730-6.

\section{Kehlet 2016}

Kehlet M, Jensen LP, Schroeder TV. Risk factors for complications after peripheral vascular surgery in 3,202 patient procedures. Annals of Vascular Surgery 2016;36: $13-21$.

\section{Lane 2017}

Lane R, Harwood A, Watson L, Leng GC. Exercise for intermittent claudication. Cochrane Database of Systematic Reviews 2017, Issue 12. DOI: 10.1002/ 14651858.CD000990.pub4

\section{Le Roy 2016}

Le Roy B, Selvy M, Slim K. The concept of prehabilitation: what the surgeon needs to know?. Journal of Visceral Surgery 2016;153(2):109-12.

Lemanu 2013

Lemanu DP, Singh PP, MacCormick AD, Arroll B, Hill AG. Effect of preoperative exercise on cardiorespiratory function and recovery after surgery: a systematic review. World Journal of Surgery 2013;37(4):711-20.

\section{Levett 2016}

Levett DZH, Edwards M, Grocott M, Mythen M. Preparing the patient for surgery to improve outcomes. Best Practice and Research. Clinical Anaesthesiology 2016;30(2):145-57.

\section{Li 2013}

Li C, Carli F, Lee L, Charlebois P, Stein B, Liberman AS, et al. Impact of a trimodal prehabilitation program on functional recovery after colorectal cancer surgery: a pilot study. Surgical Endoscopy 2013;27(4):1072-82.

Luo 2016

Luo H, Yang H, Huang B, Yuan D, Zhu J, Zhao J. Geriatric nutritional risk index (GNRI) independently predicts amputation In chronic critical limb ischemia (CLI). PLoS One 2016;11(3):e0152111.

\section{Minnella 2017}

Minnella EM, Bousquet-Dion G, Awasthi R, ScheedeBergdahl C, Carli F. Multimodal prehabilitation improves functional capacity before and after colorectal surgery for cancer: a five-year research experience. Acta Oncologica (Stockholm, Sweden) 2017;56(2):295-300.

\section{Munafo 2001}

Munafo MR, Stevenson J. Anxiety and surgical recovery. Reinterpreting the literature. Journal of Psychosomatic Research 2001;51(4):589-96.

Nehler 2014

Nehler MR, Duval S, Diao L, Annex BH, Hiatt WR, Rogers $\mathrm{K}$, et al. Epidemiology of peripheral arterial disease and critical limb ischemia in an insured national population. Journal of Vascular Surgery 2014;60(3):686-695.e2.

\section{Norgren 2007}

Norgren L, Hiatt WR, Dormandy JA, Nehler MR, Harris KA, Fowkes FGR. Inter-society consensus for the management of peripheral arterial disease (TASC II). Journal of Vascular Surgery 2007;45(1):S5-S67.

Owens 2012

Owens CD, Kim JM, Hevelone ND, Gasper WJ, Belkin M, Creager MA, et al. An integrated biochemical prediction model of all-cause mortality in patients undergoing lower extremity bypass surgery for advanced peripheral artery disease. Journal of Vascular Surgery 2012;56(3):686-95.

\section{Parmar 1998}

Parmar MK, Torri V, Stewart L. Extracting summary statistics to perform meta-analyses of the published literature for survival endpoints. Statistics in Medicine 1998;17(24): 2815-34.

\section{Pescatello 2014}

Pescatello LS, American College of Sports Medicine. ACSM's Guidelines for Exercise Testing and Prescription. Philadelphia: Wolters Kluwer/Lippincott Williams \& Wilkins Health, 2014.

\section{Pierson 2001}

Pierson LM, Herbert WG, Norton HJ, Kiebzak GM, Griffith P, Fedor JM, et al. Effects of combined aerobic and resistance training versus aerobic training alone in cardiac rehabilitation. Journal of Cardiopulmonary Rehabilitation 2001;21(2):101-10.

\section{Playforth 1987}

Playforth MJ, Smith GM, Evans M, Pollock AV. Preoperative assessment of fitness score. British Journal of Surgery 1987;74(10):890-2.

\section{Powell 2016}

Powell R, Scott NW, Manyande A, Bruce J, Vögele C, Byrne-Davis LMT, et al. Psychological preparation and postoperative outcomes for adults undergoing surgery under general anaesthesia. Cochrane Database of Systematic Reviews 2016, Issue 5. DOI: 10.1002/14651858.CD008646.pub2

\section{RevMan 2014 [Computer program]}

Nordic Cochrane Centre, The Cochrane Collaboration. Review Manager 5 (RevMan 5). Version 5.3. Copenhagen: 
Nordic Cochrane Centre, The Cochrane Collaboration, 2014.

\section{Santa Mina 2014}

Santa Mina D, Clarke H, Ritvo P, Leung YW, Matthew AG, Katz J, et al. Effect of total-body prehabilitation on postoperative outcomes: a systematic review and metaanalysis. Physiotherapy 2014;100(3):196-207.

Sato 2010

Sato H, Carvalho G, Sato T, Lattermann R, Matsukawa $\mathrm{T}$, Schricker T. The association of preoperative glycemic control, intraoperative insulin sensitivity, and outcomes after cardiac surgery. Journal of Clinical Endocrinology and Metabolism 2010;95(9):4338-44.

\section{Selvin 2004}

Selvin E, Erlinger TP. Prevalence of and risk factors for peripheral arterial disease in the United States: results from the National Health and Nutrition Examination Survey, 1999-2000. Circulation 2004;110(6):738-43.

Tierney 2007

Tierney JF, Stewart LA, Ghersi D, Burdett S, Sydes MR Practical methods for incorporating summary time-to-event data into meta-analysis. Trials 2007;8:16.

Valkenet 2011

Valkenet K, van de Port IGL, Dronkers JJ, de Vries WR Lindeman E, Backx FJG. The effects of preoperative exercise therapy on postoperative outcome: a systematic review. Clinical Rehabilitation 2011;25(2):99-111.

\section{Walburn 2009}

Walburn J, Vedhara K, Hankins M, Rixon L, Weinman J. Psychological stress and wound healing in humans: a systematic review and meta-analysis. Journal of Psychosomatic Research 2009;67(3):253-71.

Waton 2017

Waton S, Johal A, Heikkila K, Cromwell D, Loftus I, Boyle J. National Vascular Registry: 2017 Annual report. www.vsqip.org.uk/content/uploads/2018/05/2017-NVRAnnual-Report.pdf. London: The Royal College of Surgeons of England, (accessed 9 July 2019).

Yalçin 2006

Yalçin AS. Emerging therapeutic potential of whey proteins and peptides. Current Pharmaceutical Design 2006;12(13): $1637-43$

\section{Zhang 2014}

Zhang JQ, Curran T, McCallum JC, Wang L, Wyers MC, Hamdan $\mathrm{AD}$, et al. Risk factors for readmission after lower extremity bypass in the American College of Surgeons National Surgery Quality Improvement Program. Journal of Vascular Surgery 2014;59(5):1331-9.

* Indicates the major publication for the study

\section{ADDITIONAL TABLES}

Table 1. Summary of findings

Prehabilitation compared with standard care for peripheral arterial disease (PAD)

Patient or population: adults with PAD undergoing lower limb surgery

Settings: hospital

Intervention: prehabilitation ${ }^{1}$

Comparison: standard care ${ }^{2}$

\begin{tabular}{|c|c|c|c|c|c|c|}
\hline \multirow[t]{3}{*}{ Outcomes } & \multicolumn{2}{|c|}{$\begin{array}{l}\text { Illustrative comparative risks* } \\
(95 \% \mathrm{CI})\end{array}$} & \multirow[t]{3}{*}{$\begin{array}{l}\text { Relative effect } \\
\text { (95\% CI) }\end{array}$} & \multirow{3}{*}{$\begin{array}{l}\text { Number of par- } \\
\text { ticipants } \\
\text { (studies) }\end{array}$} & \multirow{3}{*}{$\begin{array}{l}\text { Quality of the } \\
\text { evidence } \\
\text { (GRADE) }\end{array}$} & \multirow[t]{3}{*}{ Comments } \\
\hline & Assumed risk & $\begin{array}{l}\text { Corresponding } \\
\text { risk }\end{array}$ & & & & \\
\hline & Standard care & Prehabilitation & & & & \\
\hline $\begin{array}{l}\text { 30-day mortal- } \\
\text { ity }\end{array}$ & \multicolumn{2}{|c|}{ Study population } & $\begin{array}{l}\mathbf{R R} \\
\text { [value] ([value] } \\
\text { to [value]) }\end{array}$ & $\begin{array}{l}\text { [value] } \\
\text { ([value]) }\end{array}$ & $\begin{array}{l}\text { [Delete as } \\
\text { appropriate] } \\
\oplus \bigcirc \bigcirc \bigcirc \\
\text { very low } \\
\oplus \oplus \bigcirc \bigcirc\end{array}$ & \\
\hline
\end{tabular}

Presurgery conditioning interventions (prehabilitation) in adults undergoing lower limb surgery for peripheral arterial disease (Protocol) 
Table 1. Summary of findings (Continued)

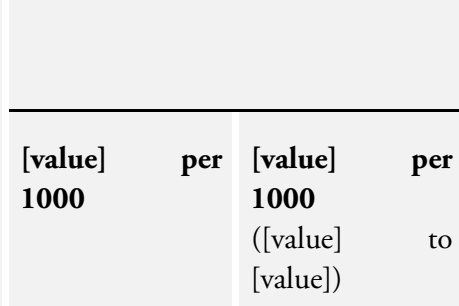

low

$\oplus \oplus \oplus \bigcirc$

moderate

$\oplus \oplus \oplus \oplus$

high

[value])

Postoperative The mean [out- The mean [out-

complications $^{3}$ come] ranged come] in the in(follow-up) across control tervention groups from groups was [value][measure] [value] [lower/ higher] [(value to value lower/higher)]

$\begin{array}{ll}\text { [value] } & \text { [Delete as } \\ \text { ([value]) } & \text { appropriate] } \\ & \oplus \bigcirc \bigcirc \bigcirc \\ & \text { very low } \\ & \oplus \oplus \bigcirc \bigcirc \\ & \text { low } \\ & \oplus \oplus \oplus \bigcirc \\ \text { moderate } \\ \oplus \oplus \oplus \oplus \\ \text { high }\end{array}$

high

\begin{tabular}{|c|c|c|c|c|c|}
\hline \multirow{2}{*}{$\begin{array}{l}\text { Re-admission } \\
\text { (within } 30 \text { days } \\
\text { of surgery) }\end{array}$} & \multicolumn{2}{|l|}{ Study population } & \multirow{2}{*}{$\begin{array}{l}\text { RR } \\
\text { [value] ([value] } \\
\text { to [value]) }\end{array}$} & \multirow{2}{*}{$\begin{array}{l}\text { [value }] \\
\text { ([value }])\end{array}$} & \multirow{2}{*}{$\begin{array}{l}\text { [Delete as } \\
\text { appropriate] } \\
\oplus \bigcirc \bigcirc \bigcirc \\
\text { very low } \\
\oplus \oplus \bigcirc \bigcirc \\
\text { low } \\
\oplus \oplus \oplus \bigcirc \\
\text { moderate } \\
\oplus \oplus \oplus \oplus \\
\text { high }\end{array}$} \\
\hline & $\begin{array}{l}\text { [value] per } \\
1000\end{array}$ & $\begin{array}{ll}\text { [value] } & \text { per } \\
1000 & \\
([\text { value }] & \text { to } \\
[\text { value }]) & \end{array}$ & & & \\
\hline \multirow{2}{*}{$\begin{array}{l}\text { One-year } \\
\text { survival }\end{array}$} & \multicolumn{2}{|l|}{ Study population } & \multirow{2}{*}{$\begin{array}{l}\text { RR } \\
\text { [value] ([value] } \\
\text { to [value]) }\end{array}$} & \multirow{2}{*}{$\begin{array}{l}\text { [value }] \\
\text { ([value]) }\end{array}$} & \multirow{2}{*}{$\begin{array}{l}\text { [Delete as } \\
\text { appropriate] } \\
\oplus \bigcirc \bigcirc \bigcirc \\
\text { very low } \\
\oplus \oplus \bigcirc \bigcirc \\
\text { low } \\
\oplus \oplus \oplus \bigcirc \\
\text { moderate } \\
\oplus \oplus \oplus \oplus \\
\text { high }\end{array}$} \\
\hline & $\begin{array}{l}\text { [value] per } \\
1000\end{array}$ & $\begin{array}{lr}\text { [value] } & \text { per } \\
\mathbf{1 0 0 0} & \\
\text { ([value] } & \text { to } \\
\text { [value] }) & \end{array}$ & & & \\
\hline $\begin{array}{l}\text { Changes } \\
\text { in fitness prein- } \\
\text { terven- } \\
\text { tion and postin- } \\
\text { tervention } \\
\text { (follow-up) }\end{array}$ & $\begin{array}{l}\text { The mean [out- } \\
\text { come] ranged } \\
\text { across control } \\
\text { groups from } \\
\text { [value][measure] }\end{array}$ & $\begin{array}{l}\text { The mean [out- } \\
\text { come] in the in- } \\
\text { tervention } \\
\text { groups was } \\
\text { [value] [lower/ } \\
\text { higher] } \\
\text { [(value to value }\end{array}$ & & $\begin{array}{l}\text { [value }] \\
\text { ([value]) }\end{array}$ & $\begin{array}{l}\text { [Delete as } \\
\text { appropriate] } \\
\oplus \bigcirc \bigcirc \bigcirc \\
\text { very low } \\
\oplus \oplus \bigcirc \bigcirc \\
\text { low } \\
\oplus \oplus \oplus \bigcirc\end{array}$ \\
\hline
\end{tabular}

Presurgery conditioning interventions (prehabilitation) in adults undergoing lower limb surgery for peripheral arterial disease (Protocol) II Copyright @ 2019 The Cochrane Collaboration. Published by John Wiley \& Sons, Ltd. 


\begin{tabular}{|c|c|c|c|c|}
\hline & & lower/higher)] & & $\begin{array}{l}\text { moderate } \\
\oplus \oplus \oplus \oplus \\
\text { high }\end{array}$ \\
\hline $\begin{array}{l}\text { Changes in psy- } \\
\text { chological } \\
\text { health } \\
\text { presurgery and } \\
\text { postsurgery } \\
\text { (follow-up) }\end{array}$ & $\begin{array}{l}\text { The mean [out- } \\
\text { come] ranged } \\
\text { across control } \\
\text { groups from } \\
\text { [value][measure] }\end{array}$ & $\begin{array}{l}\text { The mean [out- } \\
\text { come] in the in- } \\
\text { tervention } \\
\text { groups was } \\
\text { [value] [lower/ } \\
\text { higher] } \\
\text { [(value to value } \\
\text { lower/higher)] }\end{array}$ & $\begin{array}{l}\text { [value] } \\
\text { ([value]) }\end{array}$ & $\begin{array}{l}\text { [Delete as } \\
\text { appropriate] } \\
\oplus \bigcirc \bigcirc \bigcirc \\
\text { very low } \\
\oplus \oplus \bigcirc \bigcirc \\
\text { low } \\
\oplus \oplus \oplus \bigcirc \\
\text { moderate } \\
\oplus \oplus \oplus \oplus \\
\text { high }\end{array}$ \\
\hline $\begin{array}{l}\text { Changes } \\
\text { in health related } \\
\text { QoL scores } \\
\text { presurgery and } \\
\text { postsurgery } \\
\text { (follow-up) }\end{array}$ & $\begin{array}{l}\text { The mean [out- } \\
\text { come] ranged } \\
\text { across control } \\
\text { groups from } \\
\text { [value][measure] }\end{array}$ & $\begin{array}{l}\text { The mean [out- } \\
\text { come] in the in- } \\
\text { tervention } \\
\text { groups was } \\
\text { [value] [lower/ } \\
\text { higher] } \\
\text { [(value to value } \\
\text { lower/higher)] }\end{array}$ & $\begin{array}{l}\text { [value] } \\
\text { ([value]) }\end{array}$ & $\begin{array}{l}\text { [Delete as } \\
\text { appropriate] } \\
\oplus \bigcirc \bigcirc \bigcirc \\
\text { very low } \\
\oplus \oplus \bigcirc \bigcirc \\
\text { low } \\
\oplus \oplus \oplus \bigcirc \\
\text { moderate } \\
\oplus \oplus \oplus \oplus \\
\text { high }\end{array}$ \\
\hline
\end{tabular}

*The basis for the assumed risk (e.g. the median control group risk across studies) is provided in footnotes. The corresponding risk (and its 95\% CI) is based on the assumed risk in the comparison group and the relative effect of the intervention (and its $95 \% \mathrm{CI}$ ). CI: confidence interval; QoL: quality of life; PAD: peripheral arterial disease; RR: risk ratio.

GRADE Working Group grades of evidence

High quality: further research is very unlikely to change our confidence in the estimate of effect.

Moderate quality: further research is likely to have an important impact on our confidence in the estimate of effect and may change the estimate.

Low quality: further research is very likely to have an important impact on our confidence in the estimate of effect and is likely to change the estimate.

Very low quality: we are very uncertain about the estimate.

${ }^{1}$ Prehabilitation is a multimodal conditioning intervention consisting of three components, including exercise, psychological, and nutritional care prior to having a surgical procedure.

${ }^{2}$ Standard care is a preoperative assessment and relevant preparation prior to surgery, which may include: blood and urine tests, and information given on what will happen before, during, and after the operation.

${ }^{3}$ Postoperative complications will include non-fatal cardiovascular events (myocardial infarction, heart failure, or stroke), pulmonary complications (hypoxia, atelectasis, pneumonia, respiratory failure), haemorrhage, and surgical site infection.

Presurgery conditioning interventions (prehabilitation) in adults undergoing lower limb surgery for peripheral arterial disease (Protocol) 12 Copyright () 2019 The Cochrane Collaboration. Published by John Wiley \& Sons, Ltd. 


\section{A P P E N D I C E S}

\section{Appendix I. CENTRAL search strategy}

\#1 MESH DESCRIPTOR Arteriosclerosis 946

\#2 MESH DESCRIPTOR Arteriolosclerosis 0

\#3 MESH DESCRIPTOR Arteriosclerosis Obliterans 78

\#4 MESH DESCRIPTOR Atherosclerosis 1061

\#5 MESH DESCRIPTOR Arterial Occlusive Diseases 819

\#6 MESH DESCRIPTOR Intermittent Claudication 825

\#7 MESH DESCRIPTOR Ischemia 1542

\#8 MESH DESCRIPTOR Peripheral Vascular Diseases EXPLODE ALL TREES 2783

\#9 (atherosclero* ${ }^{*}$ or arteriosclero* ${ }^{*}$ or PVD or PAOD or PAD ):TI,AB,KY 12285

\#10 ((arter* or vascular or vein* or veno* or peripher*) near3 (occlus* or reocclus* or re-occlus* ${ }^{*}$ or steno* or restenos* ${ }^{*}$ or obstruct* $^{*}$ or lesio* or block* or harden* or stiffen* or obliter*)):TI,AB,KY 10672

\#11 (peripheral near3 dis*):TI,AB,KY 4875

\#12 (claudic* or IC):TI,AB,KY 4130

\#13 (isch* or CLI):TI,AB,KY 32430

\#14 arteriopathic:TI,AB,KY 7

\#15 dysvascular*:TI,AB,KY 23

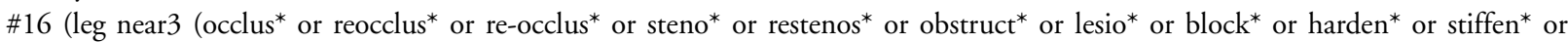
obliter $\left.{ }^{*}\right)$ :TI,AB,KY 130

\#17 (limb near3 (occlus* or reocclus* or re-occlus* or steno* or restenos* or obstruct* or lesio* or block* or harden* or stiffen* or obliter*)):TI,AB,KY 227

\#18 ((lower near3 extrem*) near3 (occlus* or reocclus* or re-occlus* or steno* or restenos* or obstruct* or lesio* or block* or harden* or stiffen* or obliter*)):TI,AB,KY 101

\#19 ((iliac or femoral or popliteal or femoro* or fempop* or crural) near3 (occlus* or reocclus* or re-occlus* or steno* $^{*}$ or restenos* ${ }^{*}$ obstruct* or lesio* or block* or harden* or stiffen* or obliter*)):TI,AB,KY 1546

\#20 MESH DESCRIPTOR Leg 2801

\#21 MESH DESCRIPTOR Iliac Artery 159

\#22 MESH DESCRIPTOR Popliteal Artery 304

\#23 MESH DESCRIPTOR Femoral Artery 904

\#24 MESH DESCRIPTOR Tibial Arteries 38

\#25 ((femor* or iliac or popliteal or fempop* or crural or poplite* or infrapopliteal or inguinal or femdist* or inguinal or infrainquinal

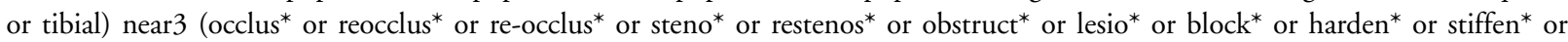
obliter*)):TI,AB,KY 1731

\#26 \#1 OR \#2 OR \#3 OR \#4 OR \#5 OR \#6 OR \#7 OR \#8 OR \#9 OR \#10 OR \#11 OR \#12 OR \#13 OR \#14 OR \#15 OR \#16 OR \#17 OR \#18 OR \#19 OR \#20 OR \#21 OR \#22 OR \#23 OR \#24 OR \#25 60427

\#27 MESH DESCRIPTOR Exercise EXPLODE ALL TREES 20318

\#28 MESH DESCRIPTOR Exercise Therapy EXPLODE ALL TREES 10938

\#29 (Active living): TI,AB, KY 74

\#30 (Active travel):TI,AB,KY 8

\#31 (Circuit training):TI,AB,KY 176

\#32 (Cross train*):TI,AB,KY 49

\#33 Cross-train*:TI,AB,KY 49

\#34 (martial art*):TI,AB,KY 141

\#35 (Motor activity):TI,AB,KY 4578

\#36 (Physical activit*):TI,AB,KY 18716

\#37 tennis:TI,AB,KY 696

\#38 (Water exercise*):TI,AB,KY 81

\#39 (Weight train*):TI,AB,KY 365

\#40 Ambulation:TI,AB,KY 2111

Presurgery conditioning interventions (prehabilitation) in adults undergoing lower limb surgery for peripheral arterial disease (Protocol)

Copyright @ 2019 The Cochrane Collaboration. Published by John Wiley \& Sons, Ltd. 
\#41 Badminton:TI,AB,KY 31

\#42 Cycling:TI,AB,KY 3852

\#43 Cyclist*:TI,AB,KY 943

\#44 Dance:TI,AB,KY 487

\#45 Dancer:TI,AB,KY 21

\#46 Dancing:TI,AB,KY 321

\#47 Exercis*:TI,AB,KY 69661

\#48 Golf*:TI,AB,KY 119

\#49 Gymnastic*:TI,AB,KY 220

\#50 gym:TI,AB,KY 280

\#51 Jogging:TI,AB,KY 285

\#52 Judo:TI,AB,KY 45

\#53 Karate:TI,AB,KY 26

\#54 Rowing:TI,AB,KY 198

\#55 Run:TI,AB,KY 9870

\#56 Running:TI,AB,KY 4348

\#57 Swim*:TI,AB,KY 914

\#58 Treadmill:TI,AB,KY 6111

\#59 Walk*:TI,AB,KY 18624

\#60 Weight-training:TI,AB,KY 337

\#61 \#27 OR\#28 OR \#29 OR\#30 OR\#31 OR \#32 OR \#33 OR\#34 OR \#35 OR\#36 OR\#37 OR \#38 OR\#39 OR\#40 OR \#41 OR \#42 OR \#43 OR\#44 OR \#45 OR \#46 OR\#47 OR \#48 OR \#49 OR\#50 OR\#51 OR \#52 OR \#53 OR\#54 OR\#55 OR\#56 OR \#57 OR \#58 OR \#59 OR \#60 104074

\#62 before:TI,AB,KY 148468

\#63 prior:TI,AB,KY 59779

\#64 preoperative:TI,AB,KY 24094

\#65 pre-op:TI,AB,KY 309

\#66 pre-surgical:TI,AB,KY 289

\#67 \#62 OR \#63 OR \#64 OR \#65 OR \#66 214009

\#68 \#61 AND \#67 23902

\#69 prehabilit*:TI,AB,KY 139

\#70 prehab:TI,AB,KY 30

\#71 \#68 OR \#69 OR \#70 23947

\#72 \#26 AND \#71 1827

\section{CONTRIBUTIONS OFAUTHORS}

JP: conceived the review question, developed the protocol, co-ordinated protocol development, completed the first draft, made an intellectual contribution, edited the protocol, guarantor of the review, approved the final version prior to submission

SP: developed the protocol, made an intellectual contribution, edited the protocol, approved the final version prior to submission GS: conceived the review question, developed the protocol, made an intellectual contribution, edited the protocol, approved the final version prior to submission

AH: developed the protocol, made an intellectual contribution, edited the protocol, approved the final version prior to submission

LI: developed the protocol, made an intellectual contribution, edited the protocol, approved the final version prior to submission

$\mathrm{CH}$ : made an intellectual contribution, approved the final version prior to submission

IC: conceived the review question, developed the protocol, made an intellectual contribution, edited the protocol, approved the final version prior to submission

Presurgery conditioning interventions (prehabilitation) in adults undergoing lower limb surgery for peripheral arterial disease (Protocol) 14 Copyright (๑) 2019 The Cochrane Collaboration. Published by John Wiley \& Sons, Ltd. 


\section{DECLARATIONSOF INTEREST}

JP: none known.

SP: none known.

GS: has received speaker's fees from BSN Medical and his academic department has, in the past, received unconditional funding from Diomed/Angiodynamics. This was used to help fund a research nurse to assist with objective assessments in the context of RCTs.

AH: none known.

LI: none known.

$\mathrm{CH}$ : none known.

IC: none known.

\section{SOURCES OF SUPPORT}

\section{Internal sources}

- No sources of support supplied

\section{External sources}

- Chief Scientist Office, Scottish Government Health Directorates, The Scottish Government, UK. The Cochrane Vascular editorial base is supported by the Chief Scientist Office.

\section{NOTES}

We have based parts of the Methods section of this protocol on a standard template established by Cochrane Vascular. 